\section{Trauma relived}

After Shocks: The Poetry of Recovery for Life-shattering Events

Tom Lombardo, editor

Santa Lucia Books; 2008

386 pp US\$19.95

$\mathrm{W}$

ithin the medical humanities literature, After Shocks follows several anthologies that focus specifically on illness, but here, editor Tom Lombardo argues that poetry is a valuable vehicle for recovery from many forms of both physical and emotional suffering. He deserves credit for nudging our awareness beyond a narrow focus on physical illness and urging a broader understanding of what conditions call for healing. This is an ambitious anthology on life traumas.

In 1985, the death of Lombardo's wife led him to read and write poems on his loss and, eventually, to begin this collection, of which he is not only editor, but also a contributor and publisher. But his apparent eagerness to make this book commercially successful works against its literary appeal. The cover text trumpets "115 poets from 15 nations," as if bigger is inherently better. And his own introduction, 3 forewords and 5 blurbs on the back cover all tout After Shocks as a comprehensive poetic textbook on tragedy.

In addition to this introductory overreaching, the effectiveness of the book's structure is debatable. Each of $12 \mathrm{sec}-$ tions is entitled "Recovery from [a specific 'life-shattering event']," yet these events often feel too broad or too narrow. "Loss of a Spouse" overlaps with "Divorce or Loss of Lover." Many, like "Loss of Innocence," could justify their own books. To proceed, the reader must set aside misgivings about this structure and the claims of comprehensiveness.

If After Shocks was full of outstanding poetry, such doubts might matter less. But there is a tendency to favour breadth over depth, quantity over quality. Not that the poetry here is poor. Most is competent, but little is striking. Despite the cover's tilted lettering in the

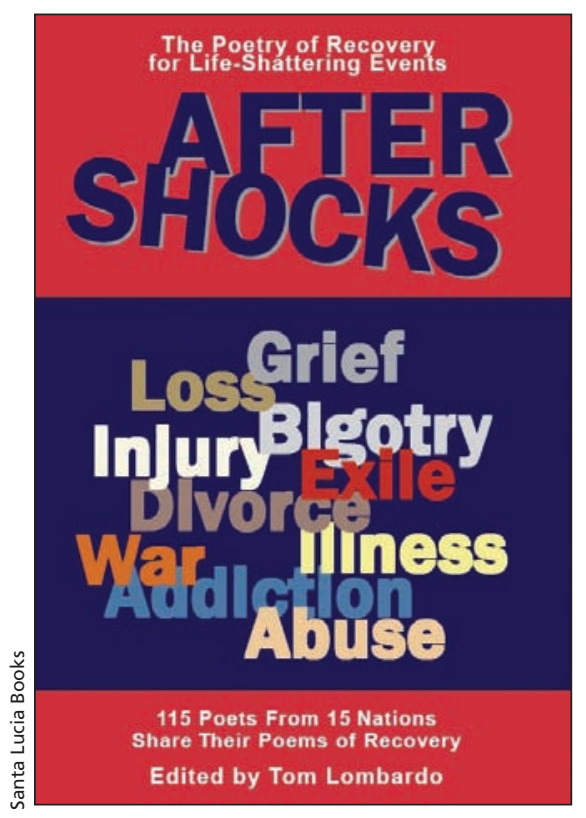

word "Shocks," suggestive of earthquake-calibre upheaval, the disruptive effect of these traumas is not often mirrored in the poems, which are, in general, stylistically unadventurous and calmly regretful in tone. Does this reflect the conventionality of Lombardo's editorial taste, or does recovery necessarily involve this degree of distancing from the raw emotion of the event? One contributor says of a piece grieving the loss of her husband, "I couldn't have written the poem any sooner than I did," and, indeed, Wordsworth once defined poetry as "powerful feelings recollected in tranquility." But it's not unreasonable to hope that even if the poems could not have been written in the midst of powerful emotion, skilled poets can nonetheless recreate that emotion, and not situate us so consistently in a tepid tranquility.

Such is too often the case here, as fine lines leap out from poems otherwise muted and unremarkable. Of Donald Hall's 4-page "Letter After a Year", only his description of visiting his wife's grave with the dog is refreshingly unexpected.

And in Laurel Blossom's 14-page "The Intemperate Zone," which is a rambling chronicle of a struggle with alcoholism, lines of exceptional succinctness stand out, such as "I used to go out to walk the dog and forget the dog."

Fortunately, Israeli poet Meir
Wieseltier's excellent work extends to whole poems; his 4 pieces in "Recovery from Bigotry" have real bite and power. One poem, "Daddy and Mommy Went to the Movies, Ilana Stays Alone in the Armchair Looking at a Gray Book," describes a naïve child's encounter with documentation of the Holocaust.

She turns the pages, naked uncles so naked and skinny, run and even aunties with fannies showing and others in pajamas as in a show with yellow cloth stars sewed on. And everybody so ugly and thin, and big round eyes like chickens.

It's awfully weird, so gray. Ilana has pencils - red and blue and green and yellow and pink.

We know what's coming, and part of us reacts with discomfort at the prospect of a child defacing a book of such sober history. Yet as she

...draws with great flair glasses and funny faces on all of them she registers an innocent's protest against the forces that strip people of their liveliness, their humour, their distinct and colourful personalities, and ultimately their lives.

Lombardo's inclusion of so many themes, poets and nationalities is clearly intended to demonstrate his contention that recovery poetry is a subgenre of real breadth. Still, it's hard to avoid the conclusion that fewer poems, more astutely organized and as powerful as Wieseltier's, might have made a more convincing case for this poetry's importance.

\section{Glen Downie MFA \\ Poet \\ Toronto, Ont.}

Mr. Downie has published 6 books of poetry; Loyalty Management won the Toronto Book Award. In 1999, he was the writer-in-residence at the Medical Humanities Program, Dalhousie University, Halifax, Nova Scotia. 